\title{
Determinants of the Recent Rise in Childhood Mortality in Sub-Saharan Africa: Evidence from Kenya Demographic and Health Surveys, 1990 - 2003
}

\author{
Collins O. Opiyo ${ }^{1 *}$ and Monika Sawhney ${ }^{2}$ \\ 1 Technical Adviser, United Nations Population Fund, Tanzania Country Office, 11 Ocean Road, Sea \\ View, Box 9182 Dar es Salaam, Tanzania. Phone: 255 - 222 - 163500. Email: opiyo@unfpa.org \\ ${ }^{2}$ Assistant Professor and Director Bachelors of Public Health, College of Health Professions, \\ Marshall University, One John Marshall Drive, Huntington, WV 25755, USA. \\ Phone: 001 - 304 - 696 -2602. Email: sawhney@marshall.edu
}

\begin{abstract}
Childhood mortality rates in Kenya increased in the 1990s and early 2000s. Evidence from Kenya Demographic Health Survey (KDHS) data shows increase in under-5 mortality rate by 26 percent from 91 in 1993 to II5 in 2003. This study examined factors associated with the rise in childhood mortality in Kenya. Micro-level data were obtained from KDHS. Macro-level data were gathered from government administrative records and comprised indicators of access and utilization of health services. Proportional hazards model was used to deconstruct factors associated with rise in childhood mortality. The results showed that that macro factors, particularly high HIV/AIDS prevalence and the general deterioration in the quality of childcare, were largely responsible for the rise in childhood mortality in the 1990s and early 2000s. Other factors believed to be also strongly associated with early childhood deaths during this period include malaria prevalence and subnational differences in culture and child care practices.
\end{abstract}

Keywords: Kenya; child mortality; determinants; emographic Health Survey

\section{Résumé}

Les taux de mortalité infantile au Kenya a augmenté dans les années 1990 et au début des années 2000. Preuve du Kenya Demographic Health Survey (KDHS ) données montre l'augmentation du taux de mortalité des moins de 5 par 26 pour cent, passant de 91 en 1993 à III en 2003. Cette étude a examiné les facteurs associés à l'augmentation de la mortalité infantile au Kenya. Données au niveau micro ont été obtenus à partir de KDHS. Données macro-économiques ont été recueillies à partir des dossiers administratifs gouvernementaux et d'indicateurs comprenant des accès et l'utilisation des services de santé. Modèle des risques proportionnels a été utilisé pour déconstruire les facteurs associés avec la montée de la mortalité infantile. Les résultats ont montré que ce que les facteurs macroéconomiques, la prévalence particulièrement élevée $\mathrm{du} \mathrm{VIH}$ / sida et la détérioration générale de la qualité des services de garde , étaient en grande partie responsables de la hausse de la mortalité infantile dans les années 1990 et au début des années 2000 . D'autres facteurs soupçonnés d'être aussi fortement associée à des décès de la petite enfance au cours de cette période comprennent la prévalence du paludisme et des différences infranationales dans la culture et la garde d'enfants pratiques.

Mots clé: le Kenya; la mortalité infantile; les determinants; et l'enquête démographique et de s

\footnotetext{
* Corresponding author: Dr. Collins O. Opiyo

Technical Adviser, United Nations Population Fund, Tanzania Country Office, 11 Ocean Road, Sea View, Box 9182

Dar es Salaam, Tanzania. Phone: 255 - 222 - 163500; Email: opiyo@unfpa.org
} 


\section{Introduction}

Childhood mortality rates increased in Kenya from the 1990s following decades of decline. As shown in Figure I, under-five mortality rate increased by 26 percent - from 9I to II 5 per 1000 live births - from early 1990s to early 2000s. This trend was in sharp contrast to that witnessed during the preceding period where the rate dropped from over 250 to about 100 per 1000 live births in the late 1940s and mid-1980s respectively (Hill 1993). The reversal raised interesting research questions. Was the rise an empirical result or an artifact of the data? What were its dynamics? What were its determinants?

Figure 1. Estimated levels and trend in under-5 mortality in Kenya

Rate per 1000

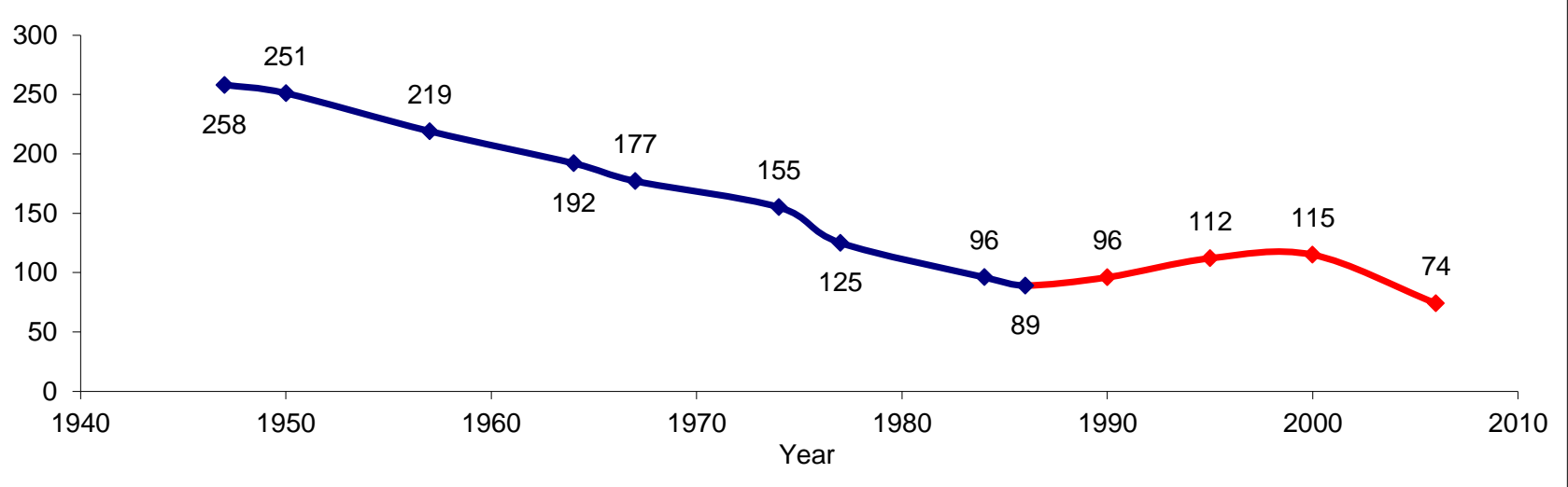

Figure I. Estimated levels and trend in under-five mortality in Kenya.

Source: ROK 1990, 1994, 1996, 1999, 2002, 2004, 2010; Hill 1993; Brass and Jolly 1993.

Yet the reversal was not unique to Kenya. Following impressive declines after World War II further early childhood mortality decline in many African countries appeared to decelerate, stall, or even reverse after mid-1980s (Hill and Pebley 1989; Hill 1993; Zuberi et al. 2003). The deterioration was observed mainly in countries with relatively high prevalence of HIV/AIDS (Adetunji 2000; Amouzou and Hill 2005), and among those experiencing major economic reversals (National Research Council 1993). However, the evidence was thought to be largely inconclusive, that more than a 'handful' factors are were involved ((Rutstein 2000), including specific country contexts (Ewbank, Henin, and Kekovole 1986 and Kibet 1991), and/or a possible shift in the structural composition of the determinants such as observed in some developing countries (Arriaga and Davis 1969; Preston 1975, 1980; Gwatkin 1980; and Caldwell 1986).

In sum the underlying causes of the recent increase in early childhood mortality may have a complex structure, which may vary from one country (context) to another. This calls for a comprehensive country-specific analysis - where it has occurred - to deconstruct the factors associated with it.

\section{Literature review and theoretical framework}

The underlying causes of the recent increase in early childhood mortality may be a consequence of many variables associated with one or a combination of the following broad classification of factors: adverse changes in the correlates of child survival; increased death clustering among certain sub-groups occasioned by the changes in population dynamics; and shifting structure of relationships.

Besides favorable changes in family formation variables, suspicion is strong on the role of HIV/AIDS. In addition to its devastating direct impact on survival, HIV/AIDS has far-reaching indirect impacts that generally result in resource inadequacy for child health services and other forms of care both at the household and national level for many countries in sub-Saharan Africa where HIV/AIDS prevalence is high, including Kenya (Timaeus 1998; Adetunji 2000; Hill et al. 2004; Whiteside and Boerma 2004; Garene and Gakusi 2005; GaigbeTogbe and Weibberger 2005; Omariba D.W.R. et al. 2007; Wafula S. W. et al 20I2).

Factors associated with differences in culture and child care practices and ecology may also be subsumed in the substantial regional differentials in early childhood mortality levels and trends in Kenya. Historically, excessive deaths of infants and children 
have been noted among the inhabitants of Nyanza Province, in parts of the Rift Valley and Western provinces, and in the Coast. These patterns have been attributed to the high environmental burden of disease - malaria and diarrheal diseases - but cultural orientation is surmised as a factor as well (Ewbank, Henin and Kekovole 1986; Kibet 1991; McElroy et al. 200 I; Lindblade et al. 2004; Wafula W $S$ et al. 2012).

In addition many studies have documented role of individual or household socio-economic and demographic factors associated with rising levels of child mortality in Kenya. These factors include maternal education, income or well-being, place of residence, breastfeeding, water and sanitation, and access to and utilization of health (UNICEF 1990; Aaby 1992; Leroy and Garene 1992; Feyisetan and Adeokun 1992; Ewbank and Gribble 1993; Frankenberg 1995; Boerma and van Ginneken 1996; Omariba D.W.R. et al. 2007; Ombok M et al. 2010; Wafula S.W., et al. 2012; Ikamari, L.D.E. 2013; Kimani R.R and Kimani E R. 20I2).

\section{Data and methods}

\section{Data sources}

The study is based on two main types of data micro and macro level data. Micro-level data are obtained from Kenya Demographic and Health Surveys (KDHS) conducted in 1989, 1993, 1998, and 2003, covering the period when rising early childhood mortality was observed (The 2008/09 Kenya DHS dataset falls outside this period of interest and, therefore, not used in this study). Macro-level data were gathered from government administrative records and comprised district-level indicators of access and utilization of health services, other social amenities (mainly water and sanitation), adult HIV/AIDS prevalence, breastfeeding practices and child nutrition. These data represented periods or calendar years corresponding to the DHSs data sets - that is, 1989, 1993, 1998 and 2003. The final dataset constitutes pooled micro and macro data containing records of 45,690 singleton births that occurred within 10-year period of each survey, altogether covering the period 1979- 2003.

\section{Description of macro-level factors}

Based on the literature and knowledge of the socioeconomic development dynamics of Kenya during the period, data on the variables of interest were collected from Government administrative records for variables relating to access and utilization of health services, provision of social amenities, childcare practices and HIV/AIDS prevalence.
Malaria prevalence was important as well, but the data was inadequate. Full data were mostly available at the national and the provincial level only. Districtlevel data, were mostly available for the more recent periods, after 2000. To fill some of the data gaps, district-level averages were generated from the surveys data sets. The analytical period 1979-2003 was then sub-divided into roughly 5 -year periods (1979-82, 1983-87, 1988-92, 1993-97, and 199803). District averages were then obtained for each period for each variable of interest. The factors are discussed below - under each broad group.

\section{Access to health services}

These macro-level variables were all measured at the district level. An index of health access (number of persons per facility per kilometer) was constructed by dividing each district's average population in a given period by the respective number of health facilities, weighted by the squareroot of the district size in $\mathrm{km}^{2}$. The bigger the index, the less accessible are the health facilities. This index is expected to be positively associated with the hazards of death of children. Only a couple of required data points were available at district level. However, the province-level data were available for multiple years. We estimated the missing district data points by assuming the pattern of distribution of facilities by districts remained the same as that observed in the available data points - within provinces.

\section{Utilization of health services}

Macro-level variables related to utilization of health services include prenatal care, hospital delivery, vaccination coverage, and medical care. These variables were measured in percentage units at the district level. They were mostly constructed from survey responses from birth history records of children aged below 5 years. Vaccination coverage rates were based on district averages of immunization status of all children aged 12-23 months covering all main antigens (poliol, 2, 3; bcg; dpt I, 2, 3; and measles).

\section{Social amenities}

Two variables were considered, namely water supply and sanitation. Adequate (or improved) water supply is indicated by the percentage of children from households with access to piped water. Adequate (or improved) sanitation is the percentage of children from households with access to adequate toilet sanitation (flush toilet, VIP, and 
traditional pit latrine). These are the standard definitions used by $\mathrm{WHO}$.

\section{HIV/AIDS prevalence}

Data on adult HIV/AIDS prevalence was available by district from 200I-2005, but only at national level for the rest of the periods, back to 1990 (the first HIV/AIDS case in Kenya was observed in 1984). For the periods before 2000 the district averages were imputed based on the ratio of the observed district level prevalence to national prevalence. In addition, the 2003 Kenya DHS had data on HIV status of individual women of reproductive age.

\section{Child nutrition and care}

Two variables were used, namely stunting and breastfeeding duration - at district level. Stunting is critical, and preferred to wasting or underweight indices as it is a measure of chronic malnutrition and, therefore, a long term determinant of child health and mortality. District averages of stunting were easily derived from each KDHS data set to cover the corresponding period.

Breastfeeding, on the other hand, is an important measure of immunologic protection and nutrition status, which are critical for infant survival. Because the length of breastfeeding and child survival are intertwined - potentially leading to reverse causation - the duration of breastfeeding was redefined by splitting the age interval into small segments, and assigning duration according to whether the child was breastfeeding at the beginning of the segment. Other scholars have successfully experimented with a similar strategy (see Palloni and Millman 1986). Because most Kenyan children are weaned between 4 to 6 months, the length of breastfeeding was dichotomized into less than 6 months and $6+$ months.

\section{Construction of Household Wellbeing Index}

The DHS-type surveys do not collect information on income. Thus, a composite asset index was constructed to proxy household income using the procedure devised by Filmer and Pritchett (1999, 200I), and based on the principal components analysis (Dunteman 1989). Construction of this index is done at the household level, and based on household ownership of a variety of assets or use of certain household amenities, including radio, television, motorcycle, bicycle, car, telephone, refrigerator, and use of electricity. Once created the individual or household wealth status were categorized as quintiles and used in the analysis.

\section{Methods of Analysis}

Descriptive statistics are used for preliminary data analysis. The Cox regression model, a proportional hazards model with an appealing ability to fit a large variety of data without imposing a distribution to yield robust results, is used in the multivariate analysis (Allison 1995; Cleves, Gould, and Gutierrez 2004). The coefficients are examined for each period using pooled data, and applied on the differences in means between the mortality declining and rising periods to obtain the change in hazards.

\section{The proportional hazards model (Cox Regression)}

Cox regression models the hazard of an individual experiencing an event - such as death - in a multivariate framework. Given a set of $k$ covariates, $\mathbf{x}^{1}, \mathbf{x}^{2}, \ldots . \mathbf{x}^{k}$, the hazard of death of individual $i$ is given as:

$$
h_{i}(t)=h_{0}(t) \exp \left\{b_{1} x_{i 1}+\ldots+b_{k} x_{i k}\right\}
$$

This equation implies that the hazard of death for each individual at time $t$ is the product of an arbitrary or unspecified but non-negative function of time, $h^{0}(t)$, and an exponential linear function of the covariates. The model is estimated using its 'log hazards' equivalent, thus:

$$
\begin{aligned}
& \quad \log h_{i}(t)=a(t)+b_{1} x_{i 1}+\ldots+b_{k} x_{i k}, \quad \text { where } \\
& a(t)=\log h_{0}(t) .
\end{aligned}
$$

\section{Analytical model}

The 45,690 children available for this analysis are split into five 5-year birth periods, namely 1979-82, 1983-87, 1988-92, 1993-97, and 1998-03. The macro-level covariates are then merged onto the pooled individual-level data by period and region/district, thereby converting the crosssectional variables into time-varying covariates. Because the macro-level variables are repetitive for all children within a region/district the Cox regression estimates are adjusted for cluster effects using robust cluster option.

\section{Results}

\section{Descriptive statistics}

Table I shows the percentage distribution of children dead by age 5 across categories of individual-level variables associated with early childhood mortality. The overall picture is that of a consistent increase in proportions dead, from 7.6 percent in 1989 to 9.5 percent in 2003. The largest differentials are observed across provinces. The proportions dead are nearly four times higher in 
Nyanza - the highest - compared to Central Province. Among socio-economic variables, large differences in proportions dead - nearly twice - are observed by mother's education and household wellbeing. No difference is observed by place of residence in 1989, but the proportions dead become larger in rural than urban areas for the subsequent surveys, although the differential never gets as large as for education and wellbeing. Large differences are also observed by birth interval, which increase over time. Additionally, higher proportions dead are observed among children with short birth intervals $(<18$ months $)$ and of high parity women

Table I Distribution of individual-level variables by proportion of children dead (by age 5 ) and survey year: Kenya, 1989-2003 DHSs

\begin{tabular}{|c|c|c|c|c|c|c|c|c|}
\hline Variable & 1989 & & 1993 & & 1998 & & 2003 & \\
\hline & Dead (\%) & $N$ & Dead (\%) & $N$ & Dead (\%) & $N$ & Dead (\%) & $N$ \\
\hline Total & 7.6 & 13119 & 8.1 & 11982 & 8.9 & 10860 & 9.5 & 9729 \\
\hline \multicolumn{9}{|c|}{ Mother's education } \\
\hline None & 9.2 & 4175 & 8.8 & 2801 & 10.7 & 1500 & 9.4 & 1413 \\
\hline Primary & 7.4 & 6905 & 9 & 6776 & 10.1 & 6727 & 10.9 & 6234 \\
\hline Secondary+ & 5.3 & 2025 & 4.7 & 2405 & 5 & 2634 & 5.2 & 2083 \\
\hline \multicolumn{9}{|l|}{ Wellbeing } \\
\hline Low & 9.1 & 5338 & 9.3 & 4390 & 10.2 & 4102 & 10.8 & 4534 \\
\hline Middle & 6.5 & 5432 & 7.7 & 5186 & 8.9 & 4778 & 9.1 & 3992 \\
\hline High & 6.9 & 2349 & 6.6 & 2406 & 5.1 & 1980 & 5.8 & 1203 \\
\hline \multicolumn{9}{|l|}{ Mother's age } \\
\hline$<20$ years & 9.6 & 2327 & 9.6 & 2127 & 12.8 & 1964 & 10.1 & 1747 \\
\hline $20-34$ years & 7 & 9083 & 7.6 & 8381 & 7.8 & 7775 & 8.9 & 6889 \\
\hline $35+$ years & 8.3 & 1709 & 8.5 & 1474 & 10.1 & 1121 & 12 & 1093 \\
\hline \multicolumn{9}{|l|}{ Residence } \\
\hline Rural & 7.6 & 11444 & 8.3 & 10531 & 9.3 & 8993 & 9.9 & 7947 \\
\hline Urban & 7.5 & 1675 & 6.4 & 1450 & 7 & 1867 & 7.6 & 1782 \\
\hline \multicolumn{9}{|l|}{ Marital Status } \\
\hline Never married & 5.1 & 722 & 7.1 & 637 & 8.5 & 592 & 6.4 & 459 \\
\hline Currently married & 7.6 & 11543 & 8 & 10300 & 8.6 & 9358 & 9.4 & 8298 \\
\hline Formerly married & 10.4 & 854 & 9.6 & 1045 & 13 & 910 & 12.1 & 972 \\
\hline \multicolumn{9}{|c|}{ Previous birth interval } \\
\hline$<18$ months & 13.8 & 1432 & 13.4 & 1144 & 14.4 & 922 & 20 & 754 \\
\hline $18+$ months & 6.4 & 9440 & 8.1 & 8449 & 8.4 & 7434 & 8.9 & 6565 \\
\hline \multicolumn{9}{|l|}{ Birth order } \\
\hline 1 & 9 & 2247 & 8.5 & 2389 & 8.4 & 2504 & 7.8 & 2409 \\
\hline $2-4$ & 7 & 5402 & 7.5 & 5234 & 8.2 & 4950 & 8.4 & 4529 \\
\hline $5+$ & 7.7 & 5471 & 8.5 & 4359 & 10.4 & 3406 & 12.6 & 2790 \\
\hline \multicolumn{9}{|l|}{ Parity } \\
\hline $\mathrm{I}-2$ & 6.8 & 1963 & 6.6 & 2333 & 6.2 & 2775 & 6 & 2561 \\
\hline $3-4$ & 6.9 & 3500 & 7.2 & 3413 & 8.2 & 3999 & 8.5 & 3235 \\
\hline $5+$ & 8.5 & 7656 & 9.1 & 6237 & 11 & 4786 & 12.5 & 3932 \\
\hline \multicolumn{9}{|l|}{ Child's sex } \\
\hline Male & 8.1 & 6571 & 8.3 & 5886 & 9.2 & 5537 & 10.7 & 4940 \\
\hline Female & 7.2 & 6548 & 7.8 & 6096 & 8.7 & 5323 & 8.3 & 4789 \\
\hline \multicolumn{9}{|l|}{ Provinces } \\
\hline Nairobi & 7 & 711 & 6.7 & 510 & 5.4 & 663 & 8 & 639 \\
\hline Central & 3.7 & 1867 & 3.6 & 1468 & 3.3 & 1003 & 4.7 & 1098 \\
\hline Nyanza & 12.6 & 2381 & 16.5 & 2012 & 17.3 & 2459 & 17.9 & 1653 \\
\hline Other & 7.1 & 8161 & 6.8 & 7992 & 7.1 & 6735 & 8.3 & 6340 \\
\hline
\end{tabular}

Source: Computed by authors from Kenyan DHS data files 


\section{Rise in early childhood mortality}

Preliminary multivariate model based on Cox regression showed that the 1989 survey did not significantly improve the multivariate model and, consequently, was dropped from the multivariate analysis models. The period 1979-82 was dropped

Table 2. Estimated relative risks (hazard ratios) of dying by age 5: Kenya, 1993-2003 DHSs as it was based on 1989 KDHS dataset only. The analysis then focused on the four categories of the period variable, namely 1983-87 (reference category), 1988-92, 1993-97, and 1998-03, the results of which are shown in Table 2.

\begin{tabular}{|c|c|c|c|c|c|c|}
\hline Variable & Model I & Model 2 & Model 3 & Model 4 & Model 5 & Model 6 \\
\hline \multicolumn{7}{|c|}{ Period of birth (Ref: 1983-87) } \\
\hline \multirow[t]{2}{*}{$1988-92$} & 1.0684 & 0.9852 & 0.9402 & $0.8509 * *$ & 0.9413 & $1.1734 * *$ \\
\hline & $(.066)$ & $(.073)$ & $(.07 I)$ & $(.069)$ & $(.072)$ & $(.073)$ \\
\hline \multirow{3}{*}{$1993-97$} & & & & $0.6276 * *$ & & $1.3256 * *$ \\
\hline & I.1757*** & 1.0371 & 1.0683 & * & $0.7577 * *$ & \\
\hline & $(.073)$ & $(.130)$ & $(.131)$ & $(.091)$ & $(.105)$ & $(.084)$ \\
\hline \multirow{3}{*}{ 1998-03 } & & & & $0.6689 * *$ & & $1.4638^{* * *}$ \\
\hline & 1.2244*** & 1.0103 & 1.0983 & * & 0.8307 & \\
\hline & $(.087)$ & $(.168)$ & $(.179)$ & $(.104)$ & $(.126)$ & $(.108)$ \\
\hline \multicolumn{7}{|l|}{ Macro-level factors (\%) } \\
\hline \multirow{2}{*}{ Access to health facility ${ }^{a}$} & & $10006 *$ & I $0010 * * * *$ & $\begin{array}{l}1.0008 * * \\
*\end{array}$ & $\begin{array}{l}1.0008^{* * *} \\
*\end{array}$ & \\
\hline & & $(.0002)$ & $(.000)$ & $(.000)$ & $(.000)$ & \\
\hline \multirow{2}{*}{ Skilled prenatal care } & & $1.0125 *$ & $\begin{array}{l}1.0200 * * * * \\
*\end{array}$ & $\begin{array}{l}1.0157 * * \\
*\end{array}$ & $\begin{array}{l}1.0170^{* * *} \\
*\end{array}$ & \\
\hline & & $(.007)$ & $(.007)$ & $(.006)$ & $(.006)$ & \\
\hline \multirow[t]{2}{*}{ Hospital delivery } & & $0.9893 * * *$ & $.9870 * * *$ & $.9894 * * *$ & $\left.0.990\right|^{* * *}$ & \\
\hline & & $(0.003)$ & $(.003)$ & $(.003)$ & $(.003)$ & \\
\hline \multirow[t]{2}{*}{ Vaccination coverage } & & $0.983 I^{* * * *}$ & $.9888 * * *$ & $.9933 *$ & $0.9938 * *$ & \\
\hline & & $(.003)$ & $(.003)$ & $(.003)$ & $(.003)$ & \\
\hline \multirow[t]{2}{*}{ Medical care } & & 1.0011 & 0.9972 & .9970 & $0.9965 * *$ & \\
\hline & & $(.002)$ & $(.002)$ & $(.002)$ & $(.002)$ & \\
\hline \multirow[t]{2}{*}{ Adequate water supply } & & & 1.0014 & 0.9995 & 1.0024 & \\
\hline & & & $(.002)$ & $(.002)$ & $(.002)$ & \\
\hline \multirow[t]{2}{*}{ Adequate toilet sanitation } & & & $.9932 * *$ & $.9937 * * * *$ & $0.9937^{* * *}$ & \\
\hline & & & $(.003)$ & $(.002)$ & $(.002)$ & \\
\hline \multirow[t]{2}{*}{$\begin{array}{l}\text { Breastfeeding } \\
\text { (6+ months) }\end{array}$} & & & $.9668 * * * *$ & $.9745 * * * *$ & $0.974 I_{* *}$ & \\
\hline & & & $(.010)$ & $(.008)$ & $(.008)$ & \\
\hline \multirow[t]{2}{*}{ Stunting (-2SD) } & & & 0.9976 & 1.0005 & 1.0004 & \\
\hline & & & $(.005)$ & $(.005)$ & $(.004)$ & \\
\hline \multirow{2}{*}{ Adult HIV prevalence } & & & & $\begin{array}{l}\text { I.0463** } \\
*\end{array}$ & $\begin{array}{l}1.0411 * * \\
*\end{array}$ & \\
\hline & & & & $(.010)$ & $(.007)$ & \\
\hline
\end{tabular}

Hazard ratios estimated by Cox

regression

Macro-level variables are in percentages

a Persons per facility per $K M$

*** $p<.01 ; * * p<.05 ; * p<.10$

() Robust standard errors

Model I: Period only

Model 2: Model I + Access and utilization of health services

Model 3: Model $2+$ water supply, toilet sanitation, breastfeeding, stunting

Model 4: Model $3+$ HIV prevalence

Model 5: Model $4+$ individual-level variables;

Model 6: Model I + individual level variables 
Six models were run towards ascertaining the factors associated with the rise in early childhood mortality. Model I - the period model - shows that the risk of under-five death increased in the 1990s, by 18 percent in 1993-97 and 22 percent in 1998-03 relative to 1983-87. The increase is highly significant for both periods.

Model 2 - the access to health services model, which examines the period effects of health access and utilization - shows that controlling for health service access and utilization variables greatly attenuated the increase in hazards of under-five death. Indeed, the effect of access is apparently strengthened by health service utilization variables, especially by differences in vaccination coverage and delivery care.

Model 3 shows that adjusting for differences in other forms of childcare and the quality of the living environment accentuate the influence of health service access and utilization. Breastfeeding and toilet sanitation are especially important in this regard, both of which were strongly associated with reduction in childhood mortality risk. These variables generally deteriorated after 1990 as shown in Table 2.

Model 4 shows that HIV/AIDS had a huge adverse effect on child survival after 1990. Adjusting for differences in HIV/AIDS prevalence completely and significantly reversed the under-five mortality trend. In particular, Model 4 shows that in the absence of HIV/AIDS under-five mortality would have continued to decline into the 1990s, by about 15,37 , and 33 percent in 1988-92, 1993-97 and 1998-03 respectively, relative to 1983-87. The largest effect occurred during 1993-97, which coincides with the peak impact of HIV/AIDS on overall mortality in Kenya. Overall, a percentage increased in HIV/AIDS prevalence increases the risk of under-five mortality by nearly 5 percent, ceteris paribus.
In Model 5 controlling for individual-level variables associated with early childhood mortality significantly attenuated the effects of period and HIV prevalence to the extent that only the 1993-97 period coefficient remained statistically significant, but altogether failed to reverse the increasing trend in childhood mortality risks. Thus, context clearly exerts the dominant influence on childhood mortality trends during this period. Further, Model 6 shows that the net effect of the individual-level variables was an increase in risk of deaths under-five of 17, 33, and 46 percent in 1988-92, 1993-97, and 1998-03 respectively relative to 1983-87. The overall implication is that the individual-level variables had a net reduction effect on hazards of under-five deaths after 1990. However, the effect was not sufficient to overcome the combined effect on childhood mortality of increasing HIV/AIDS prevalence and the general deterioration in the quality of childcare.

Indeed, Models 5 and 6 showed that substantial differentials in childhood mortality risk remain among micro factors. As expected, risks were substantially lower among higher socio-economic sub-groups - as much as 30 percent among women with secondary and higher education - thereby continuing to provide the much needed cushioning against increasing childhood mortality risks.

The final models are run on the $2003 \mathrm{KDHS}$ alone - the only data set with micro-level HIV/AIDS information. The results, shown in Table 3 , shed further light on the detrimental impact of HIV/AIDS on child survival. Children of HIV-positive women were 2.5 times more likely to die compared to children of HIV-negative women, which is consistent with similar studies in Sub-Saharan Africa. Overall, the models based on 2003 KDHS data alone suggests that the net effect of changes in individual factors was to reduce childhood mortality risk. Table 3 also shows that the beneficial effect of breastfeeding was sustained, while the importance of access to health services was enhanced in the era of HIV/AIDS in Kenya. 
Table 3. Relative risks of dying by age 5: Kenya, 2003 DHS

\begin{tabular}{|c|c|c|c|}
\hline Variable & Model I & Model 2 & Model 3 \\
\hline \multicolumn{4}{|l|}{ Period of birth (Ref. 1993-97) } \\
\hline \multirow[t]{2}{*}{ 1998-03 } & 0.9747 & $1.3010 * *$ & 1.1830 \\
\hline & $(.080)$ & $(.162)$ & $(.182)$ \\
\hline \multicolumn{4}{|l|}{ Macro-level variables (\%) } \\
\hline \multirow{2}{*}{ Access to health facility ${ }^{a}$} & 1.0005 & & $1.0010 *$ \\
\hline & $(.001)$ & & $(.001)$ \\
\hline \multirow[t]{2}{*}{ Skilled prenatal care } & $1.0135 *$ & & 1.0063 \\
\hline & $(.007)$ & & $(.008)$ \\
\hline \multirow{2}{*}{ Hospital delivery } & $0.9912 *$ & & 0.9960 \\
\hline & $(.004)$ & & $(.005)$ \\
\hline \multirow{2}{*}{ Vaccination coverage } & 0.9981 & & 1.0027 \\
\hline & $(.004)$ & & $(.004)$ \\
\hline \multirow[t]{2}{*}{ Medical care } & 1.0011 & & 0.9990 \\
\hline & $(.002)$ & & $(.003)$ \\
\hline \multirow[t]{2}{*}{ Adequate water supply } & 0.9975 & & 1.0036 \\
\hline & $(.002)$ & & $(.003)$ \\
\hline \multirow[t]{2}{*}{ Adequate toilet sanitation } & 0.9982 & & 0.9974 \\
\hline & $(.003)$ & & $(.003)$ \\
\hline \multirow[t]{2}{*}{ Breastfeeding (6+ months) } & $0.9611 * * *$ & & $0.9667 * * *$ \\
\hline & $(.010)$ & & $(.011)$ \\
\hline \multirow[t]{2}{*}{ Stunting (-2SD) } & 1.0001 & & 1.0072 \\
\hline & $(.006)$ & & $(.008)$ \\
\hline \multirow[t]{2}{*}{ Adult HIV prevalence (sentinel surveillance) } & I.0532**** & & $1.0295 * * *$ \\
\hline & $(.011)$ & & $(.010)$ \\
\hline \multicolumn{2}{|l|}{ Mother HIV+ (Survey) } & $2.5418 * * *$ & $2.0250 * * *$ \\
\hline \multicolumn{2}{|l|}{ Positive } & $(.396)$ & $(.373)$ \\
\hline \multicolumn{4}{|l|}{$\begin{array}{l}\text { Notes: } \\
* * * *_{p}<.01 ; * * p<.05 ; * p<.10 \\
\text { () Robust standard errors }\end{array}$} \\
\hline \multicolumn{4}{|l|}{${ }^{a} \quad$ Persons per facility per $K M$} \\
\hline \multicolumn{4}{|l|}{ Model I: Period + macro-level variables } \\
\hline \multicolumn{4}{|l|}{ Model 2: Period + individual-level variables } \\
\hline Model 3: Model I + Model 2 & & & \\
\hline
\end{tabular}

The rise in childhood mortality: Relative variable contributions

This section builds on the preceding analysis, and aims to quantify the factors responsible for the observed increase in childhood mortality risks. The strategy involved dichotomizing the analytic period to reflect both the declining and increasing phases of childhood mortality. Because evidence adduced indicates that recent rise in childhood mortality begun after the late 1980s, following a period of sustained decline, the period variable was dichotomized as 1983-92 (declining period) and 1993-03 (rising period). First, the changes in the mean values of the variables between these periods were examined. Then Cox regression coefficients were obtained from the pooled data. Finally, these coefficients were applied on the differences in means to obtain the change in hazard between the periods. Details are shown in Table 4. Columns (I) and (2) show the mean value of each variable for each period (these are simple national averages of the individual district-level measures), while column (3) is the absolute change in the value of each variable between the periods. Multiplying the differences in means in column (3) by the Cox regression coefficients in column (4) yield the estimated changes in hazards due to each variable shown in column (5). Because Cox regression only models relative hazards, the values entered in column (5) cannot be interpreted as absolute hazards but rather as the relative changes in hazards over the period. Negative signs on this column imply net reduction in death hazards, 
and vice versa. These can be expressed as percentage changes using the formula $100 *\left(e^{\hat{\beta}}-1\right)$ , where $\hat{\beta}$ is the net change in hazard for each variable, shown in column (6).

Table 4 shows that the column sum is 0.1156 , implying a 12 percent $\left[100\left(e^{0.1156}-I\right)\right]$ overall increase in the hazard of under-five death between 1983-1992 and 1993-2003. Consistent with earlier observations, district-level variables drive the increase in under-five death hazards. Increased HIV prevalence was the prime mover, associated with 34.7 percent increase in risk, followed by reduction in vaccination coverage ( 11.7 percent) and in duration of breastfeeding (8.9 percent). Reductions in medical care for sick children and access to adequate toilet sanitation also acted to increase hazards although their effects were relatively small ( $1.2 \%$ and $0.2 \%$ respectively).

Table 4. Cox regression model for decomposing variable contribution to the change in under-five mortality in Kenya between 1983-92 and 1993-03

\begin{tabular}{|c|c|c|c|c|c|c|}
\hline \multirow{2}{*}{ Predictor } & \multicolumn{3}{|c|}{ Mean value of predictor } & \multirow{2}{*}{$\begin{array}{l}\text { Cox regression } \\
\text { coefficient } \\
1983-03 \\
\end{array}$} & \multicolumn{2}{|c|}{ Net change in hazard } \\
\hline & $1983-92$ & 1993-03 & Difference & & Absolute & $\%$ \\
\hline & (I) & $(2)$ & $(3)=(2)-(I)$ & $(4)$ & $(5)=(4) *(3)$ & (6) \\
\hline Access to health facility & 250.85 & 173.72 & -77.13 & $.0010 * * *$ & -0.0771 & -7.4 \\
\hline Skilled prenatal care & 90.51 & 87.38 & -3.13 & $.0194 * * *$ & -0.0607 & -5.9 \\
\hline Hospital delivery & 27.4 & 40.82 & 13.42 & $-.0116 * * *$ & -0.1557 & -14.4 \\
\hline Vaccination coverage & 73.63 & 55.74 & -17.89 & $-.0062 *$ & 0.1109 & $\mathrm{II} .7$ \\
\hline Medical care & 60.48 & 57.30 & -3.18 & $-.0036 *$ & 0.0114 & 1.2 \\
\hline Adequate water supply & 32.29 & 26.94 & -5.35 & $.0033^{*}$ & -0.0177 & -1.8 \\
\hline Adequate toilet sanitation & 80.31 & 80.07 & -0.24 & $-.0068 * * *$ & 0.0016 & 0.2 \\
\hline Breastfeeding (6+ months) & 83.43 & 80.32 & -3.11 & $-.0273 * * *$ & 0.0849 & 8.9 \\
\hline Stunting (-2SD) & 36.3 & 34.15 & -2.15 & 0.0003 & -0.0006 & -0.1 \\
\hline HIV/AIDS prevalence & 2.21 & 11.46 & 9.25 & $.0322 * * *$ & 0.2979 & 34.7 \\
\hline \multicolumn{7}{|l|}{ Residence (ref. Rural) } \\
\hline Urban & 0.1337 & 0.1801 & 0.0464 & -0.0894 & -0.0041 & -0.4 \\
\hline \multicolumn{7}{|c|}{ Mother's education (ref. None) } \\
\hline Primary & 0.578 & 0.6349 & 0.0569 & $.2182 * *$ & 0.0124 & 1.2 \\
\hline Secondary & 0.2078 & 0.2288 & 0.0210 & $-.2753 * * *$ & -0.0058 & -0.6 \\
\hline \multicolumn{7}{|c|}{ Household wellbeing (ref. Lower) } \\
\hline Middle & 0.4343 & 0.4217 & -0.0126 & -0.058 & 0.0007 & 0.1 \\
\hline Higher & 0.1944 & 0.1469 & -0.0475 & $-.2099 * * *$ & 0.01 & 1.0 \\
\hline \multicolumn{7}{|l|}{ Maternal age (Ref. 20-34) } \\
\hline $15-19$ years & 0.1813 & 0.1772 & -0.0041 & $.3395 * * *$ & -0.0014 & -0.1 \\
\hline $35+$ years & 0.1152 & 0.1114 & -0.0038 & 0.0675 & -0.0003 & 0 \\
\hline \multicolumn{7}{|c|}{ Birth interval (ref. I8+ months) } \\
\hline Short (< 18 months) & 0.0995 & 0.0734 & -0.0261 & $.6304^{* * * *}$ & -0.0165 & -1.6 \\
\hline First birth & 0.2014 & 0.2477 & 0.0463 & $.2329 * * *$ & 0.0108 & $\mathrm{I} . \mathrm{I}$ \\
\hline \multicolumn{7}{|l|}{ Child's sex (ref. Female) } \\
\hline Male & 0.4989 & 0.506 & 0.0071 & $.1348 * * *$ & 0.001 & 0.1 \\
\hline \multicolumn{7}{|l|}{ Mother's parity (ref. 3-4) } \\
\hline I-2 children & 0.1692 & 0.302 & 0.1328 & $-.3315 * * *$ & -0.044 & -4.3 \\
\hline $5+$ children & 0.5344 & 0.3826 & -0.1518 & $.2867 * * *$ & -0.0435 & -4.3 \\
\hline \multicolumn{7}{|c|}{ Marital status (ref. married) } \\
\hline Never married & 0.0449 & 0.0585 & 0.0136 & $.2682^{* *}$ & 0.0036 & 0.4 \\
\hline Formerly married & 0.094 & 0.0863 & -0.0077 & $.2956 * * *$ & -0.0023 & -0.2 \\
\hline Overall change in hazard & & & & & 0.1156 & 12.3 \\
\hline
\end{tabular}

Notes:

$* * * p<.01 ; * * p<.05 ; * p<.10$

Access to health facility index is measured in persons per facility per kilometer

Unfavorable changes in some individual-level mortality risks, but their effects were generally small variables also facilitated the increase in childhood compared to the macro-level factors. These include 
deterioration in wellbeing and increased proportional share of births of first order to never married women. Still, other variables acted to suppress the increase in childhood mortality namely improved access to health services and some aspects of utilization (particularly increase in number of institutional deliveries), improvements in education and birth intervals, and fertility reduction.

\section{Discussion and conclusion}

The 1990s was a particularly turbulent period for child survival in post-Independence Kenya. This coincides with the period when HIV/AIDS prevalence reached epidemic proportions. In particular, high prevalence of HIV/AIDS is associated with the largest increase in childhood mortality rate during this period. In addition the 1990s also witnessed a general deterioration in maternal and child health services - particularly reduction in vaccination coverage and medical treatment of childhood illnesses. The association with HIV/AIDS is likely. The peak HIV/AIDS prevalence in the latter half of the 1990s must have constrained resources hitherto meant for maternal and child health services, thereby leading to the observed deterioration of these services and, consequently, child survival. The reduction in the length of breastfeeding was also strongly associated with increase in childhood mortality. Again, the association with HIV/AIDS is consistent with the notion that breastfeeding by HIV-positive mothers increases the likelihood of vertical transmission of the virus and, hence discouraged. Studies show that the impact of HIV/AIDS has resulted in depletion and re-allocation of both national and household resources in Sub-Saharan Africa. At household level there are lost earnings, increasing medical expenditure, reductions in food consumption and, subsequently, malnutrition among young children. Indeed the recent DHS and Service Provision Assessment Surveys show increasing inaccessibility to adequate maternal and child health services in Kenya in the recent past. Disparities in access and use of health services, particularly in vaccination coverage, hospital delivery, and medical care were strongly associated with the increase in childhood mortality risks from the 1990s. Overall, intracountry disparities in HIV/AIDS prevalence, vaccination coverage and breastfeeding length together account for more than 50 percent of the increase in under-five death hazards between 1983 92 and 1993-03. In general, the individual-level variables had a net reduction effect on the risks of childhood mortality. However, their combined effect was not sufficient to offset the combined negative impact on childhood mortality of increasing HIV/AIDS prevalence and the general deterioration in the quality of childcare.

The results show that that macro factors, particularly high HIV/AIDS prevalence and the general deterioration in the quality of childcare, were largely responsible for the rise in childhood mortality in the 1990s and early 2000s. However, their impact was attenuated by favorable micro-level factors such as increasing maternal education and significant reduction in birth rates.

Although the Kenyan government pursues various programs to improve child health and mortality, the greatest challenge is integrating them into a comprehensive program that takes due consideration of the multifaceted nature of the factors involved. It is recommended that the Government and its development partners implement an integrated program that is welltargeted to the needs and locations of children at different stages of the life course. The program should include a monitoring and evaluation (M\&E) framework to facilitate effective implementation, and a common-basket funding approach to enhance efficiency through synergy and prioritization. It should also seek to strengthen the HMIS to improve on collection of time-series data to facilitate trend analyses.

\section{Limitations}

Other factors believed to be also strongly associated with early childhood deaths during the period examined include malaria prevalence and cultural practices. Many studies have attributed the child survival disadvantage observed in Coast, Western and Nyanza provinces to these factors. Indeed a bivariate model in this study showed a strong correlation between outpatient malaria prevalence and deaths of children under-five years ( $r$-squared $=$ 0.57 ). However, data limitations precluded these variables from this study.

In addition, the birth histories analyzed in this study comprised children born within 10 years of each survey, while the mothers' background characteristics referred to the periods immediately preceding each survey. This might create a temporal disconnection whereby the mothers' characteristics somewhat misrepresent children born farther away from the survey. The resulting distortions may be minimal if any since no fundamental transformation or changes in the said background characteristics during the 10-year period preceding each survey was observed. 


\section{Acknowledgement:}

None

\section{Author's contribution:}

This note is submitted to support publication of the manuscript titled "Determinants of the recent rise in childhood mortality in Sub-Saharan Africa" Evidence from Kenya Demographic and Health Surveys, 1900 - 2003. Both the authors have contributed sufficiently in preparation and submission of this manuscript. Contents of this manuscript have never been previously published, however this manuscript is adapted from "Opiyo, C. O. 2009. "The Recent Rise of Childhood Mortality in Sub-Saharan Africa: The Case of Kenya." Unpublished Doctoral Dissertation submitted to University of Pennsylvania, USA".

\section{References}

Adetunji, J. 2000. "Trends in Under-5 Mortality Rates and the HIV/AIDS Epidemic." Bulletin of the World Health Organization 78, (10): 1200 1206.

Allison, P.D. 1995. Survival Analysis Using SAS: A practical Guide. SAS Press.

Amouzou, A. and K. Hill. 2005. "Child Mortality and Socioeconomic Status in Sub-Saharan Africa." African Population Studies 19, (I): I-I2.

Arriaga E. E., and K. Davis. 1969. "The Pattern of Mortality Change in Latin America." Demography 6, (3): 223-242.

Brass, W. and C. L. Jolly (Eds.) 1993. Population Dynamics of Kenya. Population Dynamics of SubSaharan Africa: Working Group on Kenya. National Academy Press.

Caldwell, J.C. 1986. "Routes to Low Mortality in Poor Countries." Population and Development Review, 12, (2): 17I-220.

Cleves, M.A., W.W. Gould, and R.G. Gutierrez. 2004. An Introduction to Survival Analysis Using Stata.

Dunteman, G. H. 1989. Principal Components Analysis. Sage University Press.

Ewbank, D.C., R. Henin and J. Kekovole. 1986. “An Integration of Demographic and Epidemiologic Research on Mortality in Kenya." Chapter III, in Determinants of Mortality Change and Differentials in Developing Countries 1986, edited by Department of International Economic and Social Affairs, United Nations.

Filmer, D., and L. Pritchett. 1999. "The Effect of Household Wealth on Educational Attainment: Evidence From 35 Countries." Population and Development Review 25, (I): 85-120.
Filmer, D., and L. Pritchett 200I. "Estimating Wealth Effects Without Expenditures Data-or Tears: An Application to Educational Enrollments in States of India." Demography 38, (I): I I 5-I 32.

Gwatkin, D. R. 1980. "Indications of Change in Developing Country Mortality Trends: The End of an Era?" Population and Development Review 6, (4): 615- 644.

Hill, A. 1993. "Trends in Childhood Mortality." In Foote, K.A., K. H. Hill and L.G. Marrtin eds. Demographic Change in Sub-Saharan Africa. National Research Council. National Academy Press: Washington, D.C.

Hill, K. and A. R. Pebley. 1989. "Child Mortality in the Developing World". Population and Development Review I5, (4): 657-687.

Ikamari, L.D.E. 2013. "Regional variation in neonatal and post-neonatal mortality in Kenya. African Population Studies, 27 (I): I- 15.

Kazembe L.N., Kleinschmidt I., \& Sharp B.L. 2006. "Patterns of malaria-related hospital admissions and mortality among Malawian children: an example of spatial modelling of hospital register data". Malaria Journal 5, (93).

Kibet, M. 1981. "Differential mortality in Kenya. "Unpublished Master's thesis. University of Nairobi.

Kimani R.R. E., Kimani E.R.R. 2012. "Determinants of under-five mortality in rural and urban Kenya". Rural and Remote Health 12: 1812.

Lindblade, K.A., T.P. Eisele, J.E. Gimnig et al. 2004. "Sustainability of Reductions inn Malaria Transmission and Infant Mortality in Western Kenya With Use of Insecticide-Treated Bednets." Journal of American Medical Association 291, (2I): 2572-2580.

McElroy, P.D., F.O. Ter Kule, A.W. Hightower et al. 200I. "All-Cause Mortality Among Young Children in Western Kenya: Asembo Bay Cohort Project." American Journal of Tropical Medicine and Hygiene 64. (I, 2) s: 18-27.

National Research Council. 1993. Demographic Effects of Economic Reversals in Sub-Saharan Africa. National Academy Press, Washington, D.C.

Omariba, D.W.R., Beujot, R., Rajulton, F. 2007. "Determinants of infant and child mortality in Kenya: an analysis controlling for frailty effects". Population Research and Policy Review 26 (4): 299-321.

Ombok, M., Adazu K., Odhiambo, F., Bayoh, N., Kiriinya, R., Slutsker, L., Hamel, M.J., Williamson, 
J., Hightower A., Laserson, K.F., Feikin, D.R. 2010. "Geospatial distribution and determinants of child mortality in rural western Kenya 20022005". Tropical Medicine and International Health 15, (4): 423-433.

Opiyo, C. O. 2009. "The Recent Rise of Childhood Mortality in Sub-Saharan Africa: The Case of Kenya." Unpublished Doctoral Dissertation submitted to University of Pennsylvania, USA.

Palloni, A., and S. Millman. 1986. "Effects of interbirth intervals and breastfeeding on infant and early childhood mortality." Population Studies 40, (2):2I5-236.

Preston, S. H. 1980. "Causes and Consequences of Mortality Declines in Less Developed Countries during the Twentieth Century." In R.A. Easterlin, ed. Population and Economic Change in Developing Countries. Chicago: University of Chicago Press, pp. 289-327.

Preston, S.H. 1975. "The changing relation between mortality and level of economic development." Population Studies 29, (2): 23I-248.

Republic of Kenya (ROK). 1990. Kenya Demographic and Health Survey 1989. NCPD, CBS, ORC Macro.

Republic of Kenya (ROK). 1994 Kenya Demographic and Health Survey 1993 .NCPD, CBS, ORC Macro.

Republic of Kenya (ROK). 1996. Kenya Population Census 198, Volume III: Analytical Report on Mortality. Central Bureau of Statistics. Nairobi.
Republic of Kenya (ROK). 1997. "AIDS in Kenya." Sessional Paper No. 4 of 1997. Ministry of Health. Nairobi.

Republic of Kenya (ROK). 1999. Kenya Demographic and Health Survey 1998. NCPD, CBS, ORC Macro.

Republic of Kenya (ROK). 2004. Kenya Demographic and Health Survey 2003. CBS and ORC Macro.

Republic of Kenya (ROK). 2010. Kenya Demographic and Health Survey 2008-09. KNBS.

Rutstein, S. O. 2000. "Factors Associated With Trends in Infant and Child Mortality in Developing Countries During the 1990s." Bulletin of the World Health Organization 78, (10): I256-1270.

Silue K.D., Raso G., Yapi A. et al. 2008. Spatiallyexplicit risk profiling of Plasmodium falciparum infections at a small scale: a geostatistical modelling approach. Malaria Journal 7: 28752877.

Wafula, S.W., llamari, D.E., and K'Oyugi, B.O., 2012. "In search for an explanation to the upsurge in infant mortality in Kenya during the 1988-2003 period. BMC Public Health (12): 44I.

Zuberi, T., A. Sibanda, A. Bawah and A. Noumbissi. 2003. "Population and

African Society." Annual Review of Sociology 29: 465-86. 